\title{
Antimicrobial Effect of Cyclamen persicum Tuber Extracts Against Bacteria and Candida Species
}

\section{Mu'ad Al-zuabe, Yazan Ismail*, Diya Hasan, Hussein Alhrout, Safaa Al-Zeidaneen, Yanal Albawarshi and Eman Abu-Hamra}

Department of Allied Medical Sciences, Zarqa University College, Al-Balqa Applied University, Al-Salt, Jordan.

\begin{abstract}
The antimicrobial resistant microorganisms will take us again to an era where a simple infection could lead to serious illness and death, interest in using medicinal plants as a source of new antimicrobials has increased. Cyclamen persicum is a traditional medicinal plant that showed to have some medicinal effects. The aim of the present study was to evaluate the antimicrobial effect of $C$. persicum tuber water, acetone, ethanol and methanol extracts on different pathogenic bacteria and candida. It was found that $C$. persicum tuber acetone, ethanol and methanol extracts have antibacterial effect on many Gram positive and Gram negative bacteria specially $S$. pyogenes, $S$. aureus, $E$. faecalis, $P$. mirabilis, K. pneumoniae, E. cloacae, P. aeruginosa and S. flexneri. C. persicum tuber acetone, ethanol and methanol extracts also showed great antifungal effect against all Candida used in this study. The study also reported extracting saponin from $C$. persicum tubers methanol extract.
\end{abstract}

Keywords: Cyclamen persicum tubers, Antimicrobial effect, Saponin.

*Correspondence: Y.Ismail@bau.edu.jo; +962 786676547.

(Received: 12 October 2018; accepted: 01 December 2018)

Citation: Mu'ad Al-zuabe, Yazan Ismail, Diya Hasan, Hussein Alhrout, Safaa Al-Zeidaneen, Yanal Albawarshi and Eman Abu-Hamra, Antimicrobial Effect of Cyclamen persicum Tuber Extracts Against Bacteria and Candida Species, J Pure Appl Microbiol., 2019; 13(1):107-116 doi: 10.22207/JPAM.13.1.11

(C) The Author(s) 2019. Open Access. This article is distributed under the terms of the Creative Commons Attribution 4.0 International License which permits unrestricted use, sharing, distribution, and reproduction in any medium, provided you give appropriate credit to the original author(s) and the source, provide a link to the Creative Commons license, and indicate if changes were made. 


\section{INTRODUCTION}

Extracts of medicinal plants were used traditionally in healing infectious diseases all over the world, but since the discovery of antibiotics from fungal and bacterial sources in the mid of the $20^{\text {th }}$ century the use of plant extracts almost demolished $^{1}$. The overuse and the misuse of antimicrobials particularly in developing countries leaded to increase the prevalence of antibiotic and antifungal drug resistant worldwide ${ }^{2,3}$.The antimicrobial resistant bacteria and fungus are raising attention as a worldwide serious medical problem as shown in the world health organization (WHO) report that was published in $2014^{3}$.

The antimicrobial resistance of the common pathogenic Gram-positive bacteria (Staphylococcus, Streptococcus and Enterococcus species), Gram-negative bacteria (Enterobacter, Escherichia coli, Klebsiella, Pseudomonas, Salmonella and Shigella species) $)^{3,4}$ and Candida ${ }^{5}$, is taking us over again to the pre- antimicrobial era where a simple infection could lead to serious illness and death ${ }^{6}$. Interest in using medicinal plants as a source of new antimicrobial compounds has increased recently, especially after the fail in discovering novel antimicrobials since late $1980 \mathrm{~s}^{7,8}$.

One of the traditional medicinal plants here in Jordan is Cyclamen persicum. C. persicum is used traditionally in relieving spasm pain ${ }^{9}$ and as an anticancer medication agent, but no reports of using C. persicum tubers as a traditional antimicrobial agent. Jaradat et al. in 2015 found that $C$. persicum is rich with antioxidant compounds ${ }^{10}$. A study by Mahasneh et al. in 1999 found that the aerial plant parts of $C$. persicum have antimicrobial effects on four bacteria species, the study was on the aerial parts and reported the antimicrobial activity only'.

The aim of the present study was to evaluate the antimicrobial effect of $C$. persicum tuber water, acetone, ethanol and methanol extracts on different pathogenic bacteria and candida. The study measured the antimicrobial activity, the minimum inhibition concentration (MIC) and the minimum bactericidal/ fungicidal concentration (MBC/ MFC). The study also reported extracting saponin from $C$. persicum tubers.

\section{MATERIALS AND METHODS Tested microorganisms}

Microorganisms used in this study were five Gram positive bacteria (Bacillus subtilis, Enterococcus faecalis, Methicillin-resistant Staphylococcus aureus, Staphylococcus aureus, Streptococcus pyogenes), Seven Gram negative bacteria (Enterobacter cloacae, Escherichia coli, Klebsiella pneumoniae, Proteus mirabilis, Pseudomonas aeruginosa, Salmonella enterica, Shigella sonnei) and Four Candida species (Candida albicans, Candida tropicalis, Candida glabrata and Candida krusei). Microorganisms were obtained from microbiology laboratory, Zarqa University College- Al-Balqa Applied University, Jordan. All microorganism stocks were preserved in nutrient broth with $15 \%$ glycerol and kept in $-80^{\circ} \mathrm{C}$ freezer. Plant material collection and identification

Wild C. persicum tubers were collected during the spring (March and April) of 2017 from the North West areas of Jordan (mainly from Salt and Irbid), and were identified by the botanist Hussein Alhrout MSc, PhD (Department of Allied Medical Sciences, Al-Zarqa University College, Al-Balqa Applied University, Al-Salt, Jordan). A voucher specimen (NO. 10002) has been deposited at the Laboratory of Botany- Zarqa University College- Al-Balqa Applied University, Jordan.

\section{Plant extracts preparation}

Wild C. persicum tubers were washed to remove soil. Tubers were then homogenized using either sterile distilled water, acetone, ethanol or methanol as solvents. The homogenized mixtures were then incubated in a rotating water bath $\left(50^{\circ} \mathrm{C}, 70 \mathrm{rpm}\right)$ for 24 hours. Mixtures were then filtered three times using Whatman No. 1 filter papers. Mixtures were then centrifuged twice for 15 minute at 10000 RCF, supernatant of the water extract was then lyophilized while the acetone, ethanol and methanol extracts were evaporated in an incubator at $25^{\circ} \mathrm{C}$. Dried extracts were kept in air tight bottles and frozen at $-20^{\circ} \mathrm{C}$ till use $\mathrm{e}^{11}$. For measuring the antimicrobial effect of the $C$. persicum tubers crude extracts, a stock concentration of $400 \mathrm{mg} / \mathrm{ml}$ were prepared by using DMSO as a solvent for the acetone, ethanol and methanol extracts and distilled water for the water extract. The stocks were then diluted to the concentration of $100 \mathrm{mg} / \mathrm{ml}$ using distilled water 
and sterilized using a $0.22 \mu \mathrm{m}$ membrane filter. The sterile $100 \mathrm{mg} / \mathrm{ml}$ stock solutions were then kept at $4^{\circ} \mathrm{C}$ till use (not more than 24 hours).

\section{Antimicrobial effect measurements Antimicrobial activity assay}

The antimicrobial activity of the extracts were measured by the agar well diffusion method. Microorganism being tested was grown in Mueller Hinton broth (MHB, Thermo Scientific) at $37^{\circ} \mathrm{C}$ overnight on a rotary shaker, the growth was then diluted using $\mathrm{MHB}$ to a turbidity equivalent to the density of 0.5 McFarland standard, $250 \mu \mathrm{l}$ of the microorganism growth was then inoculated into $15 \mathrm{ml}$ of molten Mueller Hinton Agar (MHA, Thermo Scientific) and poured into petri dish. 6 $\mathrm{mm}$ diameter wells were made on the solidified $\mathrm{MHA}$, plant extract $(100 \mu \mathrm{l})$ at the designated concentration $(50,25,12.5,6.25,3.13$ and 1.56 $\mathrm{mg} / \mathrm{ml}$ ) and the negative control (solvent without plant extract) were placed separately in each well. Plates were then left at room temperature for 1 hour to allow the extracts to diffuse, plates were then incubated at $37^{\circ} \mathrm{C}$ overnight. Inhibition zones were measured from the base of the plate resting 5-7 cm above black flat surface and illuminated by reflecting light source ${ }^{11}$, inhibition zones above $9 \mathrm{~mm}$ (including the wells diameter) were only reported. Experiments were performed in duplicate and repeated independently three times.

In this study, the antimicrobial activity results $<6.25 \mathrm{mg} / \mathrm{ml}$ were reported to have a strong antimicrobial activity, while results 6.25 $25 \mathrm{mg} / \mathrm{ml}$ were reported to have a moderate antimicrobial activity, results $>25 \mathrm{mg} / \mathrm{ml}$ were reported to have weak antimicrobial activity and results $>50 \mathrm{mg} / \mathrm{ml}$ were reported to have no antimicrobial activity.

Minimum inhibitory concentration (MIC), minimum bactericidal concentration (MBC) and minimum fungicidal concentration (MFC) determination

This study measured the MIC of $C$. persicum tuber extracts at the concentrations $50,25,12.5,6.25,3.13$ and $1.56 \mathrm{mg} / \mathrm{ml}$. MIC were measured as follow, using sterile $96-$ Well microplates (Thermo Fisher) $150 \mu \mathrm{l}$ of double strength extract $(100,50,25,12.5,6.25$ and $3.13 \mathrm{mg} / \mathrm{ml}), 140 \mu \mathrm{l}$ of MHB and $10 \mu \mathrm{l}$ of tested microorganism cultured in MHB to concentration equal to $0.5 \mathrm{McF}$ arland standard were added into each well. $300 \mu \mathrm{l}$ of $\mathrm{MHB}$ were used as negative control, $290 \mu$ l of MHB with $10 \mu$ l of microorganism cultured in MHB were used as positive control. We included a blank for each concentration of the bacterial plant extract mixture, which contained $150 \mu \mathrm{l}$ of the designed double strength extract and $150 \mu \mathrm{l}$ of MHB. Plates were then incubated at $37^{\circ} \mathrm{C}$ overnight. After incubation, turbidity of each well was measured using a microplate reader (Bio-Rad). The MIC is the lowest concentration of the extract agent that inhibited the growth of a microorganism (no change in turbidity compared to the blank). Each MIC experiment was made in duplicate and repeated three times.

To measure the MBC and MFC, $25 \mu \mathrm{l}$ of each concentration of the bacterial plant extract mixture obtained in the MIC wells was subculture (in triplicates) on MHA, the subcultures were then incubated at $37^{\circ} \mathrm{C}$ overnight. $\mathrm{MBC}$ and $\mathrm{MFC}$ is the lowest concentration at which no microorganism growth (colonies) was seen on the subculture. Each $\mathrm{MBC}$ and MFC experiment was made in duplicate and repeated three times.

In this study, the MIC, MBC and MFC values $<6.25 \mathrm{mg} / \mathrm{ml}$ were reported to have a strong value, while results $6.25-25 \mathrm{mg} / \mathrm{ml}$ were reported to have a moderate value, results $>25 \mathrm{mg} / \mathrm{ml}$ were reported to have weak value and results $>50 \mathrm{mg} /$ $\mathrm{ml}$ were reported to have no MIC, MBC or MFC value.

\section{Characterization of the $C$. persicum methanol extract}

Dry C. persicum tuber methanol extract was dissolved in a mixture of methanol and hexane solvents, and left at $4^{\circ} \mathrm{C}$ overnight. The materials dissolved in the hexane layer and the precipitate portions of the extract were discarded. The material dissolved in the methanol layer was dried and further analyzed by Fourier Transform Infrared and NMR (1H and 13C) spectra using Bruker FTIR vertex 70 and Bruker Avance $400 \mathrm{MHz}$ spectrometers, respectively. The NMR chemical shifts were given in ppm relative to solvent peaks (deuterated methanol).

\section{RESULTS AND DISCUSSION}

\section{C. persicum tuber water extract antimicrobial} effect

C. persicum tuber water extract did not show any antimicrobial effect at the Gram 
positive bacteria, Gram negative bacteria and the Candida species used in this study. Using water extraction techniques such as boiling, soaking or chowing is the traditional way of extracting active compounds from medicinal plants, this way of extraction seems to be ineffective in extracting antimicrobial compounds from $C$. persicum. This result may explain why $C$. persicum is not been used traditionally as an antimicrobial agent.

\section{C. persicum tuber extracts effect at Gram positive bacteria}

Results of the antibacterial activity, MIC and $\mathrm{MBC}$ of $C$. persicum extracts on Gram positive bacteria are shown in table 1.

One of the best antibacterial effect of C. persicum on Gram positive bacteria was found against $S$. pyogenes. $C$. persicum tuber acetone, ethanol and methanol extracts showed a moderate antibacterial activity and MIC value to S. pyogenes, the extracts also showed a weak MBC value. Another promising result were found against $E$. faecalis, C. persicum tuber ethanol and methanol extracts showed a moderate antibacterial activity and MIC value to E. faecalis, and also showed a weak MBC effect to $E$. faecalis, a study by Okmen et al. in 2014 found that Cyclamen mirabile tuber (another specie of the genus Cyclamen) had an antimicrobial effect on $E$. faecalis, the study found a strong and moderate MIC value of the ethanol and the methanol extracts, respectively ${ }^{12}$. This is the first study that showed the antibacterial effect of C. persicum to S. pyogenes and E. faecalis.

C. persicum tuber acetone, ethanol and methanol extracts had moderate antibacterial activity and MIC value to $S$. aureus, but none of the extracts showed a MBC value to S. aureus. A study by Mahasneh et al. in 1999 found a good effect (inhibition zone $>8 \mathrm{~mm}$ ) of the $C$. persicum whole aerial plant parts ethanol extract, while the $C$. persicum whole aerial plant parts butanol and petroleum ether extracts showed a weak effect $^{9}$. It seems that $C$. persicum tuber and the

Table 1. Antibacterial activity, minimum inhibitory concentration (MIC) and minimum bactericidal concentration of acetone, ethanol, methanol and water extracts of $C$. persicum tubers on different pathogenic Gram positive bacteria.

\begin{tabular}{|c|c|c|c|c|c|}
\hline & Microorganism & $\begin{array}{c}\text { Extraction } \\
\text { solvent }\end{array}$ & $\begin{array}{l}\text { Activity }^{\mathrm{a}} \\
\text { (mg/ ml) }\end{array}$ & $\begin{array}{c}\text { MIC } \\
(\mathrm{mg} / \mathrm{ml})\end{array}$ & $\begin{array}{c}\mathrm{MBC} \\
(\mathrm{mg} / \mathrm{ml})\end{array}$ \\
\hline \multirow[t]{4}{*}{1.} & B. subtilis & Acetone & Nil & 50 & $\mathrm{Nil}$ \\
\hline & B. subtilis & Ethanol & Nil & Nil & $\mathrm{Nil}$ \\
\hline & B. subtilis & Methanol & 50 & 12.5 & $\mathrm{Nil}$ \\
\hline & B. subtilis & Water & $\mathrm{Nil}$ & $\mathrm{Nil}$ & $\mathrm{Nil}$ \\
\hline \multirow[t]{4}{*}{2.} & E. faecalis & Acetone & Nil & Nil & $\mathrm{Nil}$ \\
\hline & E. faecalis & Ethanol & 25 & 6.25 & 50 \\
\hline & E. faecalis & Methanol & 25 & 6.25 & 50 \\
\hline & E. faecalis & Water & Nil & $\mathrm{Nil}$ & $\mathrm{Nil}$ \\
\hline \multirow[t]{4}{*}{3.} & MRSA & Acetone & Nil & Nil & $\mathrm{Nil}$ \\
\hline & MRSA & Ethanol & Nil & Nil & Nil \\
\hline & MRSA & Methanol & Nil & Nil & Nil \\
\hline & MRSA & Water & Nil & Nil & Nil \\
\hline \multirow[t]{4}{*}{4.} & S. aureus & Acetone & 12.5 & 25 & Nil \\
\hline & S. aureus & Ethanol & 12.5 & 25 & Nil \\
\hline & S. aureus & Methanol & 25 & 12.5 & Nil \\
\hline & S. aureus & Water & $\mathrm{Nil}$ & $\mathrm{Nil}$ & $\mathrm{Nil}$ \\
\hline \multirow[t]{4}{*}{5.} & S. pyogenes & Acetone & 25 & 12.5 & 50 \\
\hline & S. pyogenes & Ethanol & 12.5 & 25 & 50 \\
\hline & S. pyogenes & Methanol & 25 & 12.5 & 50 \\
\hline & S. pyogenes & Water & $\mathrm{Nil}$ & Nil & Nil \\
\hline
\end{tabular}

${ }^{a}$ The antibacterial activity shown is the lowest extract concentration that showed a $\geq 9 \mathrm{~mm}$ inhibition zone; Nil: No result (activity, MIC or $\mathrm{MBC}$ ) was found; Results presented are the most common result of the three independent experiments, experiments were performed in duplicate and repeated independently three times. 
whole aerial plant parts have similar effects on S. aureus. Another study by Okmen et al. in 2014 found that $C$. mirabile tuber ethanol and methanol extracts had antibacterial activity to $S$. aureus and Coagulase-negative staphylococci ${ }^{13}$. The fact that C. persicum and C. mirabile tubers have similar effects to $S$. aureus may indicate that both plant have a similar antimicrobial compound.

The study showed that $B$. subtilis was weakly effected by the $C$. persicum tuber methanol and acetone extract, while the ethanol extract did not show any antimicrobial effect. The methanol extract showed a moderate MIC value and a weak antibacterial activity while the acetone extract only showed a weak MIC value. A study by Mahasneh et al. in 1999 found a weak effect of the whole aerial plant parts $C$. persicum ethanol and petroleum ether extract on Bacillus cereus a close specie to $B$. subtilis, the study also showed no effect of the $C$. persicum butanol extract on B. cereus ${ }^{9}$. It seems that, the active antimicrobial compound in $C$. persicum only have an inhibitory effects on Bacillus bacteria. A study by Okmen et al. in 2014 found that $C$. mirabile tuber ethanol and

Table 2. Antibacterial activity, minimum inhibitory concentration (MIC) and minimum bactericidal concentration (MBC) of acetone, ethanol, methanol and water extracts of Cyclamen persicum tubers on different pathogenic Gram negative bacteria.

\begin{tabular}{|c|c|c|c|c|c|}
\hline $\begin{array}{l}\text { S. } \\
\text { No. }\end{array}$ & Microorganism & $\begin{array}{c}\text { Extraction } \\
\text { solvent }\end{array}$ & $\begin{array}{l}\text { Activity }^{a} \\
\text { (mg/ml) }\end{array}$ & $\begin{array}{c}\text { MIC } \\
(\mathrm{mg} / \mathrm{ml})\end{array}$ & $\begin{array}{c}\mathrm{MBC} \\
(\mathrm{mg} / \mathrm{ml})\end{array}$ \\
\hline \multirow[t]{4}{*}{1.} & E. cloacae & Acetone & 6.25 & 12.5 & 50 \\
\hline & E. cloacae & Ethanol & 3.125 & 12.5 & 50 \\
\hline & E. cloacae & Methanol & 6.25 & 12.5 & 50 \\
\hline & E. cloacae & Water & $\mathrm{Nil}$ & $\mathrm{Nil}$ & $\mathrm{Nil}$ \\
\hline \multirow[t]{4}{*}{2.} & E. coli & Acetone & Nil & $\mathrm{Nil}$ & Nil \\
\hline & E. coli & Ethanol & 100 & 50 & $\mathrm{Nil}$ \\
\hline & E. coli & Methanol & 100 & 25 & $\mathrm{Nil}$ \\
\hline & E. coli & Water & $\mathrm{Nil}$ & $\mathrm{Nil}$ & $\mathrm{Nil}$ \\
\hline \multirow[t]{4}{*}{3.} & K. pneumoniae & Acetone & 6.25 & 6.25 & 12.5 \\
\hline & K. pneumoniae & Ethanol & 6.25 & 6.25 & 12.5 \\
\hline & K. pneumoniae & Methanol & 1.56 & 1.56 & 6.25 \\
\hline & K. pneumoniae & Water & Nil & $\mathrm{Nil}$ & $\mathrm{Nil}$ \\
\hline \multirow[t]{4}{*}{4.} & P. mirabilis & Acetone & 3.125 & 12.5 & 50 \\
\hline & P. mirabilis & Ethanol & 3.125 & 12.5 & 25 \\
\hline & P. mirabilis & Methanol & 3.125 & 12.5 & 25 \\
\hline & P. mirabilis & Water & Nil & $\mathrm{Nil}$ & Nil \\
\hline \multirow[t]{4}{*}{5.} & P. aeruginosa & Acetone & 12.5 & 12.5 & 50 \\
\hline & P. aeruginosa & Ethanol & 12.5 & 12.5 & 50 \\
\hline & P. aeruginosa & Methanol & 6.25 & 12.5 & 50 \\
\hline & P. aeruginosa & Water & $\mathrm{Nil}$ & $\mathrm{Nil}$ & $\mathrm{Nil}$ \\
\hline \multirow[t]{4}{*}{6.} & S. enterica & Acetone & Nil & $\mathrm{Nil}$ & Nil \\
\hline & S. enterica & Ethanol & Nil & Nil & $\mathrm{Nil}$ \\
\hline & S. enterica & Methanol & $\mathrm{Nil}$ & $\mathrm{Nil}$ & $\mathrm{Nil}$ \\
\hline & S. enterica & Water & Nil & $\mathrm{Nil}$ & Nil \\
\hline \multirow[t]{4}{*}{7.} & S. flexneri & Acetone & 25 & 12.5 & 50 \\
\hline & S. flexneri & Ethanol & 25 & 12.5 & 50 \\
\hline & S. flexneri & Methanol & 12.5 & 6.25 & 50 \\
\hline & S. flexneri & Water & Nil & $\mathrm{Nil}$ & Nil \\
\hline
\end{tabular}

${ }^{a}$ The antibacterial activity shown is the lowest extract concentration that showed a $\geq 9 \mathrm{~mm}$ inhibition zone; Nil: No result (activity, MIC or $\mathrm{MBC}$ ) was found; Results presented are the most common result of the three independent experiments, experiments were performed in duplicate and repeated independently three times. 
methanol extracts had an antibacterial activity on B. subtilis at a $60 \mathrm{mg} / \mathrm{ml}$ concentration ${ }^{12}$.

Finally, no antibacterial effect was shown against MRSA using any of the $C$. persicum tuber extracts. A study by Quave et al. in 2008 found that Cyclamen hederifolium tuber ethanol extract had an inhibitory effect on biofilm formation of MRSA but the study did not find a MIC value to MRSA growth $^{14}$. The antibacterial effect of $C$. persicum crude extracts on MRSA has not been previously reported.

\section{C. persicum tuber extracts effect at Gram negative bacteria}

Results of the antibacterial activity, MIC and $\mathrm{MBC}$ of $C$. persicum extracts on Gram negative bacteria are shown in table 2 .

Table 2 shows that $C$. persicum acetone, ethanol and methanol extracts had an outstanding antibacterial effect on $P$. mirabilis and $K$. pneumoniae which may have a potential use in the future. As shown in table 2, C. persicum acetone, ethanol and methanol extracts had a strong antibacterial activity and a moderate MIC and $\mathrm{MBC}$ values on $P$. mirabilis. Multidrug-resistant $P$. mirabilis have been reported and recovered worldwide, making it a major emerging problem in antimicrobial resistance ${ }^{15}$, our results show that C. persicum acetone, ethanol and methanol extract may have a potential solution to this problem. Another promising result was found in the $C$. persicum acetone, ethanol and methanol extract on $K$. pneumoniae. C. persicum methanol extract showed a strong antibacterial activity and MIC, and showed a moderate MBC value on $K$. pneumoniae. While $C$. persicum acetone and ethanol extracts showed a moderate antibacterial activity, MIC and $\mathrm{MBC}$ value on $K$. pneumoniae. Carbapenemresistant $K$. pneumoniae is a recent high concern antibiotic resistant bacteria. Scientists considers Carbapenem-resistant as the most worrying evolution in the antibiotic resistance crisis, and the fact that carbapenem resistance has a transferable mechanism makes it even a more serious matter ${ }^{16}$. Our results show that $C$. persicum methanol extract may have a potential solution to this problem.

As shown in table 2, C. persicum acetone, ethanol and methanol extracts showed a moderate antibacterial activity (exception: ethanol extract showed a strong antibacterial activity) and MIC value, and showed a weak $\mathrm{MBC}$ value on $E$. cloacae, P. aeruginosa and S. flexneri. E. cloacae is the most clinically isolated Enterobacter specie and is raising high concerns because of their ability of expressing new $\lambda$-lactamases and carbapenemases $^{17}, P$. aeruginosa is resistant to many antimicrobials and can develop resistance to any antimicrobial compound, recently the emergence of the $P$. aeruginosa carbapenem resistant strains have increased their danger ${ }^{18,19}$. S. flexneri is also resistant to broad-spectrum $\beta$-lactam ampicillin and it was found that $2 \%$ of Shigella isolates are resistant to azithromycin which is a treatment solution to carbapenemresistant bacteria when combines with colistin ${ }^{20}$. Here again $C$. persicum acetone, ethanol and methanol extracts may have potential solution to these antimicrobial drug resistant bacteria.

E. cloacae, P. aeruginosa and S. flexneriare equipped with resistance-nodulation-cell division (RND) type efflux pump which plays an important part in antibiotic resistance ${ }^{21-23}$. Chevalier et al. in 2008 found that $40 \%$ of the multidrug resistant $E$. cloacae has an antibiotic efflux pump making it even a more serious problem ${ }^{24}$. It seems that the antimicrobial compound in $C$. persicum are minimally effected by these efflux pumps.

C. persicum acetone extract did not show any antibacterial effect on $E$. coli, while $C$. persicum ethanol and methanol extracts showed week antibacterial activity and MIC value (exception: methanol extract showed a moderate MIC value), but did not show MBC value. It was found that saponins isolated from $C$. mirabile and Cyclamen coum had a very weak antibacterial activity and MIC values to both $E$. coli and $P$. aeruginosa ${ }^{25}$. Finally, C. persicum acetone, ethanol and methanol extracts did not show any antibacterial effect on S. enterica.

\section{C. persicum tuber extracts effect at Candida species}

Generally, C. persicum tuber acetone, ethanol and methanol extracts had a stronger antimicrobial effect on candida species than on bacteria species. Results of the antifungal activity, MIC and MFC of $C$. persicum extracts on Candida species are shown in table 3.

C. persicum tuber acetone, ethanol and methanol extracts has a promising antifungal results against Candida species, especially in the 
case of $C$. glabrata which the extracts (acetone, ethanol and methanol) showed a strong MIC value $(3.125 \mathrm{mg} / \mathrm{ml})$. C. persicum tuber acetone, ethanol and methanol extracts showed a moderate antifungal activity, MIC and MFC values to all other Candida species studied in this paper, exceptions is in $C$. persicum tuber acetone extract and $C$. persicum tuber ethanol extract which showed a weak MBC values to C. albicans and C. krusei, respectively. A study by Sajjadi et al. in 2016 found that triterpenoid saponins extracted from $C$. coum had antifungal effect on $C$. albicans strains and C. tropicalis strains ${ }^{26}$.

Candida causes infection called candidiasis which is recognized as the most fungal infection in the world. Invasive candidiasis is most commonly (90\%) caused by C. albicans, C. glabrata, C. tropicalis, C. parapsilosis, and C. krusei. Invasive candidiasis is a major cause of death in intensive care unit patients and patients receiving immunosuppressive drugs, patients who usually get intensive antibacterial therapy ${ }^{3,27}$. A recent publication by the WHO in 2014 reported that resistance to fluconazole (common antifungal) and echinocandins (newest antifungal agent) by Candida is increasing worldwide, this increase will complicate the control of candidiasis in the health care system ${ }^{3}$. C. persicum tuber acetone, ethanol and methanol extracts have the potential to play a role in controlling candidiasis.

Saponin extraction from $C$. persicum tuber methanol extract

\section{Characterization of methanol extract}

${ }^{1} \mathrm{H}$ and ${ }^{13} \mathrm{C}-\mathrm{NMR}$ analysis of the methanol extract revealed that the extract is composed mainly from saponins with triterpene and sugar moieties Figure 1 . The assignments of ${ }^{1} \mathrm{H}$ and ${ }^{13} \mathrm{C}$-NMR peaks are shown in Figure 1 and were done according to reported assignments of saponins ${ }^{28,29}$. The FTIR spectrum of methanol extract showed strong bands at $3324 \mathrm{~cm}^{-1}$ due to $\mathrm{O}-\mathrm{H}$ stretching, 1039 and $992 \mathrm{~cm}^{-1}$ due to $\mathrm{C}-\mathrm{O}$ stretching. Furthermore, weak absorption bands were observed at 2953 and $2872 \mathrm{~cm}^{-1}$ due to $\mathrm{C}-\mathrm{H}$ stretching, $1715 \mathrm{~cm}^{-1}$ due to $\mathrm{C}=\mathrm{O}$ stretching and $1622 \mathrm{~cm}^{-1}$ due to $\mathrm{C}=\mathrm{C}$ stretching.

Table 3. Antifungal activity, minimum inhibitory concentration (MIC) and minimum fungicidal concentration (MFC) of acetone, ethanol, methanol and water extracts of Cyclamen persicum tubers on different pathogenic Candida species

\begin{tabular}{|c|c|c|c|c|c|}
\hline & Microorganism & $\begin{array}{c}\text { Extraction } \\
\text { solvent }\end{array}$ & $\begin{array}{l}\text { Activity } \\
\text { (mg/ ml) }\end{array}$ & $\begin{array}{c}\mathrm{MIC} \\
(\mathrm{mg} / \mathrm{ml})\end{array}$ & $\begin{array}{c}\mathrm{MFC} \\
(\mathrm{mg} / \mathrm{ml})\end{array}$ \\
\hline \multirow[t]{4}{*}{1.} & C. albicans & Acetone & 12.5 & 12.5 & 50 \\
\hline & C. albicans & Ethanol & 12.5 & 12.5 & 25 \\
\hline & C. albicans & Methanol & 12.5 & 12.5 & 25 \\
\hline & C. albicans & Water & $\mathrm{Nil}$ & Nil & $\mathrm{Nil}$ \\
\hline \multirow[t]{4}{*}{2.} & C. tropicalis & Acetone & 6.25 & 6.25 & 12.5 \\
\hline & C. tropicalis & Ethanol & 6.25 & 12.5 & 25 \\
\hline & C. tropicalis & Methanol & 12.5 & 12.5 & 25 \\
\hline & C. tropicalis & Water & $\mathrm{Nil}$ & Nil & $\mathrm{Nil}$ \\
\hline \multirow[t]{4}{*}{3.} & C. glabrata & Acetone & 6.25 & 3.125 & 12.5 \\
\hline & C. glabrata & Ethanol & 6.25 & 3.125 & 12.5 \\
\hline & C. glabrata & Methanol & 6.25 & 3.125 & 12.5 \\
\hline & C. glabrata & Water & Nil & Nil & Nil \\
\hline \multirow[t]{4}{*}{4.} & C. krusei & Acetone & 12.5 & 6.25 & 25 \\
\hline & C. krusei & Ethanol & 12.5 & 6.25 & 50 \\
\hline & C. krusei & Methanol & 6.25 & 6.25 & 12.5 \\
\hline & C. krusei & Water & Nil & Nil & $\mathrm{Nil}$ \\
\hline
\end{tabular}

a The antifungal activity shown is the lowest extract concentration that showed a $\geq 9 \mathrm{~mm}$ inhibition zone; Nil: No result (activity, MIC or MFC) was found; Results presented are the most common result of the three independent experiments, experiments were performed in duplicate and repeated independently three times. 
a.
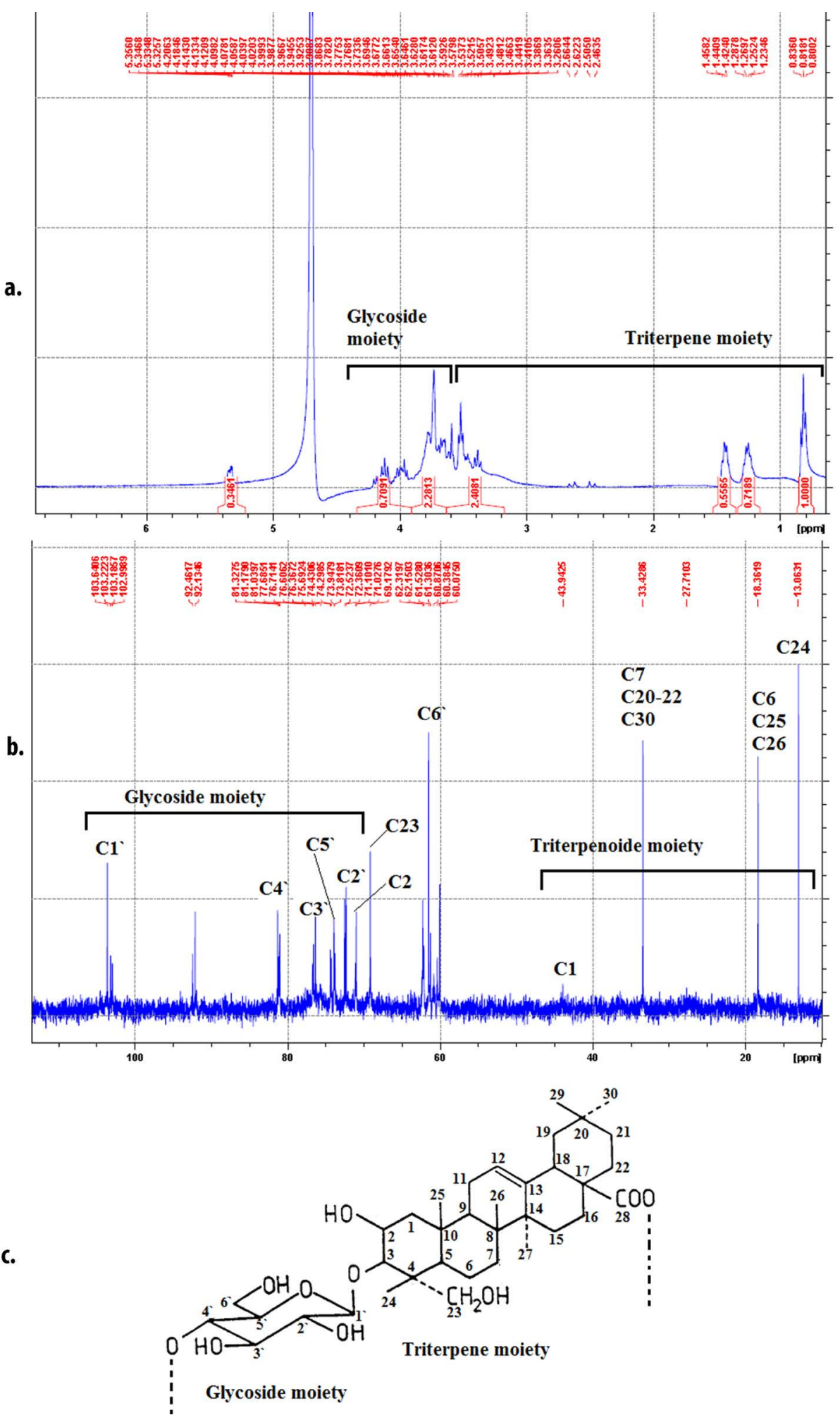

Fig. 1. ${ }^{1} \mathrm{H}-\mathrm{NMR}(\mathrm{a})$ and ${ }^{13} \mathrm{C}-\mathrm{NMR}(\mathrm{b})$ of methanol extract, and general structure of saponins with carbon numbers (c) 


\section{C. persicum tuber saponin}

Saponin is a secondary metabolite produced by different high plant species which showed antibacterial and antifungal activities against different microorganism $\mathrm{s}^{26} \mathrm{C}$. mirabile and C. coum tubers have shown to produce different saponins ${ }^{25}$. Extraction of saponin can be carried out in many ways $25,30,31$, in this paper we have shown a simple and safe way of extracting saponin, the key point was in homogenizing $C$. persicum tubers with methanol but without drying the tuber, then further purifying the crude tuber methanol extract by hexane as explained in the methodology section. The isolation of saponins from C. persicum was also reported by Mihci-Gaidi et al in $2010^{32}$ and El Hosry et al. in 2014 ${ }^{33}$.

A study by Calis et al. in 1997 showed that saponins extracted from $C$. mirabile and $C$. coum had antibacterial effects on some Gram positive bacteria (S. aureus and E. faecalis), Gram negative bacteria (E. coli and $P$. aeruginosa) and showed significant antifungal effect on many Candida species (C. albicans, C. krusei, C. parapsilosis, C. pseudotropicalis, C. stellatoidea and C. tropicalis) ${ }^{25}$. Other studies also showed that, saponin extracted from $C$. coum tubers can markedly reduce the production of pyocyanin from $P$. aeruginos $a^{34}$ and significantly inhibit $P$. aeruginosa biofilm formation when combined with ciprofloxacin ${ }^{35}$. Saponin extracted from $C$. coum tubers have also showed antifungal effects to $C$. albicans, C. tropicalis and C. krusei ${ }^{26}$. As our results are in coherence with the above studies it is mostly possibly that the main antimicrobial compound found in C. persicum tuber is saponin.

\section{CONCLUSION}

It is concluded that $C$. persicum has antibacterial effect against many Gram positive bacteria (best shown on S. pyogenes and $E$. faecalis) and Gram negative bacteria (outstanding antibacterial effect on $P$. mirabilis and $K$. pneumoniae), and a high antifungal effect against different Candida species. It seems that saponin plays a major role in these antimicrobial effects.

\section{ACKNOWLEDGEMENTS}

Authors are Thankful to Fatima Sosarby for here help all through the project, and to Zarqa University College-Balqa Applied University for all the support.

\section{CONFLICT OF INTERESTS}

The author declares that there are no conflict of interest.

\section{REFERENCES}

1. Cowan MM. Plant products as antimicrobial agents. Clin Microbiol Rev, 1999; 12(4):564-582.

2. Levy SB, Marshall B. Antibacterial resistance worldwide: Causes, challenges and responses. Nat Med, 2004; 10:122-129.

3. World Health Organization. Antimicrobial resistance: global report on surveillance. WHO, 2014.

4. Sharma R, Sharma C, Kapoor B. Antibacterial resistance: Current problems and possible solutions. Indian J Med Sci, 2005; 59:120-129.

5. Kanafani ZA, Perfect JR. Antimicrobial resistance: Resistance to antifungal agents: Mechanisms and clinical impact. Clin Infect Dis, 2008; 46(1):120-128.

6. Runcie $\mathrm{H}$. Infection in a pre-antibiotic era. $J$ Anc Dis Prev Rem, 2015, 3(125):8731.

7. Singh SB, Young K, Silver LL. What is an "ideal" antibiotic? discovery challenges and path forward. Biochem Pharmacol, 2017; 133: 63-73.

8. Silver LL. Challenges of antibacterial discovery. Clin Microbiol Rev, 2011; 24(1): 71-109.

9. Mahasneh AM, El-Oqlah AA. Antimicrobial activity of extracts of herbal plants used in the traditional medicine of jordan. J Ethnopharmacol, 1999; 64(3): 271-276.

10. Jaradat NA, Abualhasan M, Ali I. Comparison of antioxidant activities and exhaustive extraction yields between wild and cultivated cyclamen persicum, malva sylvestris and urtica pilulifera leaves. J App Pharm Sci, 2015; 5(4): 101-106

11. Ismail $\mathrm{Y}$, Wedyan $\mathrm{M}, \mathrm{Al}$-zu'abe $\mathrm{M}$, Abderrahman $\mathrm{S}$. Antimicrobial activity of rubia cordifolia: Methods to determine antimicrobial activity. Research Journal of Medicinal Plant, 2016; 10(8): 457-462.

12. Okmen G, Ceylan O, Erdal P, Arslan A. A study on antimicrobial activity of Cyclamen mirabile hildebr. root extracts against food pathogens. Journal of Anatolian Natural Sciences, 2014; 5(2): 1-7.

13. Okmen G, Erdal P, Isik D, Bayrak D. The antibacterial activities against mastitis pathogens of Cyclamen mirabile hildebr. tubers and its non-enzymatic antioxidant activities. European Journal of Experimental Biology, 2014; 4(2): 370-374.

14. Quave CL, Plano LR, Pantuso T, Bennett BC. Effects of extracts from italian medicinal plants on planktonic growth, biofilm formation and adherence of methicillinresistant staphylococcus aureus. J Ethnopharmacol, 2008; 118(3): 418-428.

15. Korytny A, Riesenberg K, Saidel-Odes L, Schlaeffer F, Borer A. Bloodstream infections caused by multidrug resistant proteus mirabilis: Epidemiology, risk factors and impact of multi-drug resistance. Infectious diseases, 2016; 48(6): 428-431.

16. Rossolini GM, Arena F, Pecile P, Pollini S. Update on the antibiotic resistance crisis. Current opinion in pharmacology, 2014; 18: 56-60.

17. Davin-Regli A, Pages JM. Enterobacter aerogenes and 
enterobacter cloacae; versatile bacterial pathogens confronting antibiotic treatment. Front Microbiol, 2015; 6 :392: Article 392

18. Woodford N, Turton JF, Livermore DM. Multiresistant gram negative bacteria: The role of high risk clones in the dissemination of antibiotic resistance. FEMS Microbiol Rev, 2011; 35(5): 736-755.

19. Vanegas JM, Cienfuegos AV, Ocampo AM, et al. Similar frequencies of pseudomonas aeruginosa isolates producing KPC and VIM carbapenemases in diverse genetic clones at tertiary-care hospitals in medellin, colombia. J Clin Microbiol, 2014; 52(11): 3978-3986.

20. Nuesch-Inderbinen $M$, Heini N, Zurfluh K, Althaus D, Hachler H, Stephan R. Shigella antimicrobial drug resistance mechanisms, 2004-2014. Emerg Infect Dis, 2016; 22(6):1083-1085.

21. Guerin F, Lallement C, Isnard C, Dhalluin A, Cattoir V, Giard JC. Landscape of resistance-nodulation-cell division (RND)-type efflux pumps in enterobacter cloacae complex. Antimicrob Agents Chemother, 2016; 60(4): 2373-2382.

22. Minagawa $\mathrm{S}$, Inami $\mathrm{H}$, Kato $\mathrm{T}$, et al. RND type efflux pump system MexAB-OprM of pseudomonas aeruginosa selects bacterial languages, 3-oxo-acylhomoserine lactones, for cell-to-cell communication. BMC microbiology, 2012; 12(1): 70.

23. Kim J, Kim S, Jeon S, Park M, Rhie H, Lee B. Resistance to fluoroquinolones by the combination of target site mutations and enhanced expression of genes for efflux pumps in Shigella flexneri and Shigella sonnei strains isolated in korea. Clinical Microbiology and Infection, 2008; 14(8): 760-765.

24. Chevalier J, Mulfinger C, Garnotel E, Nicolas P, Davin-R 'gli A, Pagus J. Identification and evolution of drug efflux pump in clinical enterobacter aerogenes strains isolated in 1995 and 2003. PLoS One, 2008; 3 (9): e3203.

25. Çaliş I, Şatana ME, Yürüker A, et al. Triterpene saponins from cyclamen mirabile and their biological activities. J Nat Prod, 1997; 60(3): 315-318.

26. Sajjadi ST, Saboora A, Mohammadi P. Comparison of aglycon and glycosidic saponin extracts of cyclamen coum tuber against Candida spp. Current Medical Mycology, 2016; 2(2): 40-44.
27. Pappas PG, Kauffman CA, Andes DR, et al. Clinical practice guideline for the management of candidiasis: 2016 update by the infectious diseases society of america. Clinical Infectious Diseases, 2015; 62(4): e1e50.

28. Bouguet Bonnet $S$, Rochd $M$, Mutzenhardt $P$, Henry $M$. Total assignment of $1 \mathrm{H}$ and $13 \mathrm{C}$ NMR spectra of three triterpene saponins from roots of silene vulgaris (moench) garcke. Magn Reson Chem, 2002; 40(9): 618-621.

29. Waller G R. Saponins: Chemistry and Pharmacology of Natural Products By K.Hostettman and A.Marston (Lausanne University, Switzerland). J. Am. Chem. Soc, 1996; 118(35): 8509- 8509.

30. Engelberth AS, Clausen EC, Carrier DJ. Comparing extraction methods to recover ginseng saponins from american ginseng (Panax quinquefolium), followed by purification using fast centrifugal partition chromatography with HPLC verification. Separation and Purification Technology, 2010; 72(1): 1-6.

31. Yuliana P, Laconi E, Wina E, Jayanegara A. Extraction of tannins and saponins from plant sources and their effects on in vitro methanogenesis and rumen fermentation. Journal of the Indonesian Tropical Animal Agriculture, 2014; 39(2): 91-97.

32. Mihci-Gaidi G, Pertuit D, Miyamoto T, et al. Triterpene saponins from cyclamen persicum. Nat Prod Commun, 2010; 5(7): 1023-1025.

33. El Hosry L, Di Giorgio C, Birer C, et al. In vitro cytotoxic and anticlastogenic activities of saxifragifolin $B$ and cyclamin isolated from Cyclamen persicum and Cyclamen libanoticum. Pharm Biol, 2014; 52(9): 11341140.

34. Ahmadbeigi Z, Saboora A, Abdi-Ali A. The effect of cyclamen coum extract on pyocyanin production by Pseudomonas aeruginosa. International Journal of Phytomedicine, 2014; 6(2): 177-181.

35. Abdi Ali A, Shafiei M, Shahcheraghi F, Saboora A, Ghazanfari T. The study of synergistic effects of $n$. butanolic cyclamen coum extract and ciprofloxacin on inhibition of Pseudomonas aeruginosa biofilm formation. Biological Journal of Microorganism, 2015; 3(12): 25-32. 